\title{
Turning Good Business Presentations Into Great Ones
}

Joan Moser

KEYWORDS: Entrepreneurship, Marketing, Angel Funding, Venture Capital, Leadership, Teaching Methods, student entrepreneurs, Student innovators.

We've all seen a presentation, sales pitch or TV commercial that really struck home. Whether it made us laugh, think or cry (or something in between), powerful messages with the right delivery inspire people to take notice and move them to action. A compelling message is especially important for entrepreneurs seeking to reach investors or convince potential customers or clients of the value of their offering.

A good teacher, like a good entertainer, first must hold his audience's attention, then he can teach his lesson. John Henrik Clarke

Through my work with the Minnesota Cup (http://carlsonschool.umn.edu/mn-cup) business plan competition, I've had the opportunity to see great business presentations both as finished products as well as works-in-progress. Behind nearly all of them are good ideas, motivated teams and worthwhile ventures. Yet only a few rise to the top.

\section{Beware of 'Show Stoppers'}

The best business presentations are assembled intentionally, and are often practiced and delivered in a way that highlights the best attributes while eliminating "disqualifiers:" mistakes or triggers that plant doubt in an audience's mind. It doesn't work if a presentation is 95\% perfect, but if the remaining $5 \%$ includes a "show stopper" that signals that the idea or the team behind it just won't make it in the real world. Along with big mistakes, "show stoppers" can include glaring omissions of data, bungled descriptions, or simply boring minutes of fluff between excellent points.

And unfortunately, sometimes a good presentation fails to become a great one for smaller, nuanced reasons. I keep in mind that the business world and business plan competitions -- like life -- don't reward second place. It's the top product, the most compelling idea, the most believable case, that wins the hearts of the investor, contest judge, client or consumer.

\section{Polish and Practice}

The pressure of presenting, then, reflects the time and effort needed to take something good and spin it into something GREAT. Do the extra competitive research. Look up and verify the facts. Craft the descriptions. Polish the visuals. Practice the timing. A great presentation is something to be proud of, particularly when it captures people's attention, engages their mind and persuades them that you and your team are to be trusted, believed and supported. Simply aiming for approval or acceptance is setting the bar too low.

In business in general, and in launching new ideas and ventures in particular, presentations are the vehicle of transformation, converting people into advocates and generating momentum. Exceptional presentations gather people and show them a compelling path to something better.

In my professional roles, I have presented and have spoken about presenting, and I would like to share two videos of speeches I have made, where I highlight and discuss what we've seen from the best-of-the-best venture presentations. Whether you are preparing for the business world or a business competition, you can take the time to learn from great examples and then set the bar high for yourselves.

\section{More ideas}

College business professors looking for more ideas to enrich the classroom experience can find them here (https://eiexchange.com/eix-in-class) .

Additional Search Terms: entrepreneurship courses, teaching ideas, teaching resources, classroom ideas, entrepreneurship classes, business schools, business school classes, entrepreneurship students, professors 